\title{
Familial Adenomatous Polyposis in Three Generations of a Single Family: A Case Study
}

\author{
Jure Murgic ${ }^{a}$ Iva Kirac $^{b} \quad Z_{\text {Zeljko Soldic }}^{a}$ Davor Tomas $^{c}$ Mario Zovak $^{d}$ \\ Ante Bolanca $^{a} \quad$ Andrzej Plawski $^{\mathrm{e}} \quad$ Tomasz Banasiewicz $^{f} \quad$ Zvonko Kusic $^{a}$ \\ ${ }^{a}$ Department of Oncology and Nuclear Medicine, ${ }^{b}$ Department of Surgical Oncology, \\ University Hospital for Tumors, ' Ljudevit Jurak Department of Pathology and \\ ${ }^{\mathrm{d}}$ Department of Surgery, Sestre milosrdnice University Hospital Center, Zagreb, Croatia; \\ ${ }^{\mathrm{e}}$ Institute of Human Genetics, Polish Academy of Sciences, and ${ }^{\mathrm{f}}$ Department of General \\ Surgery, Poznań University of Medical Sciences, Poznań, Poland
}

\section{Key Words}

Familial adenomatous polyposis $\cdot$ Rectal cancer $\cdot$ Colectomy $\cdot 2805 C>G$ substitution

\begin{abstract}
Background: Familial adenomatous polyposis (FAP) is an autosomal dominantly inherited syndrome characterized by the development of numerous polyps in the colon and rectum. If left untreated, the affected patients inevitably develop colon cancer by the age of 40 years. A resection of the colon (colectomy) or of the colon and rectum (proctocolectomy) is needed to minimize the risk of cancer. Case Presentation: We report a case of FAP through three generations of a single family, in which the grandmother and granddaughter underwent total colectomy with ileoanal anastomosis and did not develop colon cancer, while the son underwent subtotal colectomy with ileorectal anastomosis and developed recurrent rectal cancer. Data regarding timely surgery, surveillance, and chemoprevention are discussed. Conclusion: The FAP phenotype determines the type of treatment. In severe polyposis, proctocolectomy with ileoanal anastomosis seems to be the optimal method for minimizing the risk of cancer development. This case report advocates complete rectal removal, especially in cases of poor patient compliance with colonoscopic surveillance.
\end{abstract}


Murgic et al.: Familial Adenomatous Polyposis in Three Generations of a Single Family: A Case Study

\section{Background}

Familial adenomatous polyposis (FAP) is an autosomal dominantly inherited syndrome characterized by the development of numerous (hundreds to thousands) polyps in the epithelium of the large intestines [1]. Its prevalence is approximately $3-10 / 100,000$, affecting both sexes equally, with symptoms clinically manifesting themselves by the late teens and in the twenties [2]. The syndrome has a strong penetrance and in a typical course, all patients develop colorectal cancer, except when they are diagnosed and treated at an early stage. These polyps start out as adenomas in childhood, predominantly in the rectosigmoid colon, and during the second and third decades of life a malignant transformation to colorectal cancer occurs. The most common symptoms manifest in the advanced stage of FAP and include rectal bleeding, anemia, abdominal pain, tenesmus, and diarrhea. In the majority of FAP patients, a genetic disorder resulting from a germline mutation in the adenomatous polyposis gene (APC gene) is responsible for the syndrome [3].

Other common clinical features in patients with FAP include multiple gastric fundic gland polyps, duodenal, periampullar or ampullar adenomas, while extraintestinal features are desmoid tumors, congenital hypertrophy of the retinal pigment epithelium, epidermoid cysts, osteomas and thyroid cancer [4].

Of all the colorectal cancer cases worldwide, FAP accounts for less than 1\%. The majority of patients with FAP develop colorectal cancer by the age of 40 years. Therefore, different surgical strategies have been adopted to prevent cancer development in the large bowel mucosa. Herein we discuss these options based on a three-generation case.

\section{Case Presentation}

All surgical interventions, histology, extracolonic manifestations, and mutations recorded in the affected family members are presented in a timeline fashion in table 1.

Case 1

Based on colonoscopically confirmed multiple polyps in the colon and rectum at the age of 11 coupled with a family history, a male patient underwent subtotal colectomy with ileorectal anastomosis. At 39 years of age, the patient underwent restorative proctectomy with ileal pouch-anal anastomosis. Histopathology revealed hundreds of polyps with two adenocarcinomas found in the specimen - both Dukes A, Astler Coller B1 and G2 - and multiple polyps with low- to high-grade dysplasia (fig. 1, fig. 2). In 2010, at the age of 41, the patient was referred for genetic testing from the Oncology Department where he was receiving 5-fluoropirimidine/leucovorin and radiation as adjuvant treatment after Miles procedure for recurrent rectal cancer (a tumor $3 \mathrm{~cm}$ in diameter was found on ileoanal anastomosis, with 3 positive lymph nodes out of 4 isolated). The 2-year follow-up CT showed multiple lung and liver metastases and the patient was treated with a capecitabineirinotecan (XELIRI) plus bevacizumab protocol as first-line chemotherapy for metastatic colorectal cancer.

Case 2

The first clinically confirmed family member was patient No. 1's mother. In 1972, the Caucasian female, who was 24 years old at the time, underwent her first procedure, which was Miles procedure for rectal cancer located at $13 \mathrm{~cm}$ from the anal verge. On pathology specimen, several polyps with high-grade dysplasia were found in the rectal ampulla. At the 
Murgic et al.: Familial Adenomatous Polyposis in Three Generations of a Single Family: A Case Study

age of 33, a correction of sigmoidostomy was performed due to a prolapse of the stoma, and multiple polyps were found in the specimen. Clinical diagnosis of FAP was established. At the age of 42, total colectomy with Kock's reservoir was performed (around 50 polyps with lowto high-grade dysplasia were recorded on pathology report). Further follow-up was carried out according to FAP protocols, and at the age of 55, polyps were detected in the gastric antrum and duodenum and a biopsy revealed adenoma. At the age of 57, 4 large periampullar polyps were removed, one of which comprised adenocarcinoma in situ. At the age of 63 and 65 , another 2 polyps, gastric and duodenal, were removed. At the age of 45 , adenoma of the parathyroid had been removed.

Case 3

After the clinical diagnosis was established in the family, other family members were screened. In 2010, patient No. 1's 13-year-old daughter was routinely followed by colonoscopy. One year later, after high-grade dysplasia was confirmed by a polyp biopsy, total proctocolectomy with ileoanal anastomosis was performed (pathology examination of the specimen revealed more than 50 polyps, with one comprising adenocarcinoma in situ). In 2012, the patient underwent total thyroidectomy due to papillary thyroid cancer and duodenal polypectomy for duodenal tubular adenoma. No other extracolonic disease or intestinal recurrences were found.

\section{The Family}

Retrospectively, the family history revealed that patient No. 2's mother had had colon cancer at the age of 41 and that her father had died of gastric cancer at the age of 69 . However, medical records could not be retrieved. Patient No. 1's 31-year-old brother and his older daughter (14 years old) had 2 and 3 polyps on colonoscopy, respectively (adenomas on biopsy), while his younger daughter (12 years old) had negative colonoscopy.

\section{Mutations}

A family pedigree chart (fig. 3) was then constructed and genetic testing was offered to the entire family: patients No.1-3, patient No. 1's brother and his daughters. In patients No. $1-3$, a 2805C $>$ G substitution was detected. The mutation causes premature APC protein termination at the position $935 \mathrm{Y}>\mathrm{X}$. The other family members were mutation-free.

\section{Discussion}

Herein a three-generation case of FAP in a single family is presented, in which the grandmother, her son and her granddaughter had a clinical presentation of FAP. The grandmother and granddaughter remained disease-free after they had undergone total proctocolectomy, but the son developed recurrent colon cancer on ileoanal anastomosis and later metastatic disease. They were all subjected to the screening and follow-up recommended for FAP patients, and genetic testing revealed a $2805 \mathrm{C}>\mathrm{G}$ substitution, which results in a truncated protein.

Most individuals with FAP will develop colon cancer by the age of 40; therefore, prophylactic surgery is generally recommended before the age of 25 . There are 3 main surgical options for patients with FAP: (1) total proctocolectomy with Brooke ileostomy; (2) subtotal colectomy with ileorectal anastomosis, and (3) restorative proctocolectomy with the formation of an ileal reservoir and ileoanal anastomosis $[5,6]$. The treatment of choice is total colectomy; however, the removal or preservation of the rectum is a matter of contro- 
Murgic et al.: Familial Adenomatous Polyposis in Three Generations of a Single Family: A Case Study

versy. The decision to remove the rectum is influenced by the number of polyps in the rectum as well as by the family history. If there are only few polyps in the rectum, total colectomy with ileorectal anastomosis may be recommended. If the rectum is involved, then restorative proctocolectomy with ileal pouch-anal anastomosis is the treatment of choice [7]. Prophylactic surgery significantly improves the outcome of patients with FAP.

In the granddaughter's resected colon, numerous polyps were found, microscopically demonstrating high-grade epithelial dysplasia as the last stage in the multistep process of colorectal carcinogenesis. These features probably displayed a more aggressive mutation phenotype since she was only 14 years old at the time of surgery. Generally, prophylactic cancer-preventive colorectal surgery is recommended by the late teens or early twenties [8]. Half of FAP patients develop adenomas by 15 years of age but cancer development at this age is uncommon. Generally, cancer starts to develop a decade after the appearance of the polyps [9]. The optimal surgical procedure is proctocolectomy with pouch formation and ileoanal anastomosis since it completely removes all large bowel mucosa as potential origin of cancer and thereby minimizes the risk of malignancy, while preserving bowel function. For most patients, this is the procedure of choice [10]. On the other hand, patients who undergo ileorectal anastomosis are at risk, varying from 13 to 59\%, of developing rectal adenomas and carcinomas after 25 years and they demand lifelong rectal surveillance [5]. Moreover, in a subset of patients having undergone proctocolectomy, endoscopic annual surveillance of the pouch and transitional anal zone is essential since many studies have demonstrated that premalignant changes and invasive adenocarcinomas are found in the ileoanal pouch even after restorative proctocolectomy [11-13].

Patient No. 1 omitted colonoscopic surveillance between the last two surgical procedures, which might explain the extent of local recurrence. Colonoscopy and prophylactic colectomy are the primary strategies to prevent colon cancer or detect it at an early stage. The American Gastroenterology Association recommends annual sigmoidoscopy in patients with classic FAP and at-risk relatives starting at the age of 10-12 years. Patients with adenomatous polyps found on sigmoidoscopy should undergo a full colonoscopy and random biopsies to establish the severity of the polyposis [14]. The family members who are mutation-free will be surveyed by the protocols for the general population. Implementation of genetic testing that would result in standard protocols is still a matter of debate, since the tests are still not widely available and patients are not referred when indicated, leaving room for improvement in FAP treatment.

The reason why the grandmother did not have a regular follow-up or a more aggressive surgical treatment remained obscure even after a careful review of her history. We believe it might both be due to the unawareness of this syndrome at the time of the first operation and surgery planning based on sigmoidoscopy. On the other hand, the patient had not been compliant with regular follow-up until the diagnosis of FAP was made and its implication explained. This issue stresses the critical importance of lifelong follow-up and responsibility for both patients and physicians to adhere to when dealing with FAP. Several studies have demonstrated that a regular use of nonsteroidal anti-inflammatory drugs and selective COX2 inhibitors can reduce the polyp number and size in patients with FAP [15-17]. Upon these results, celecoxib was approved as adjunctive preventive treatment in patients with FAP, besides inevitable endoscopic surveillance and surgical intervention. The successful management of colonic disease implies a continuous surveillance of extracolonic disease. Patient No. 2 had surgery for parathyroid adenoma and patient No. 3 for thyroid cancer, while patient No. 2 had ampullar cancer endoscopically removed. Multidisciplinarity and, again, long-term surveillance is essential for these patients. 
Murgic et al.: Familial Adenomatous Polyposis in Three Generations of a Single Family: A Case Study

\section{Conclusion}

Patient compliance with regular and strict surveillance is an important factor when deciding on the optimal type of prophylactic surgery. Patients who are not adherent to surveillance should undergo proctocolectomy with ileal pouch-anal anastomosis. Timing and type of preventive surgery as well as compliance with preventive strategies and strict follow-up are essential for minimizing the risk of cancer development in patients with FAP.

\section{References}

Rosai J: Rosai and Ackerman's Surgical Pathology, ed 9. St. Louis, CV Mosby, 2004.

- 2 Half E, Bercovich D, Rozen P: Familial adenomatous polyposis. Orphanet J Rare Dis 2009;12:4-22.

-3 Bisgaard ML, Fenger K, Bülow S, Niebuhr E, Mohr J: Familial adenomatous polyposis (FAP): frequency, penetrance, and mutation rate. Hum Mutat 1994;3:121-125.

4 Anaya DA, Chang GJ, Rodriguez-Bigas MA: Extracolonic manifestations of hereditary colorectal cancer syndromes. Clin Colon Rectal Surg 2008;21:263-372.

-5 Aziz 0, Athanasiou T, Fazio VW, Nicholls RJ, Darzi AW, Church J, Phillips RK, Tekkis PP: Meta-analysis of observational studies of ileorectal versus ileal pouch-anal anastomosis for familial adenomatous polyposis. Br J Surg 2006;93:407-417.

-6 Bülow C, Vasen H, Järvinen H, Björk J, Bisgaard ML, Bülow S: Ileorectal anastomosis is appropriate for a subset of patients with familial adenomatous polyposis. Gastroenterology 2000;119:1454-1460.

-7 Ziv Y, Church JM, Oakley JR, McGannon E, Schroeder TK, Fazio VF: Results after restorative proctocolectomy and ileal pouch anal anastomosis in patients with familial adenomatous polyposis and coexisting colorectal cancer. Br J Surg 1996;83:1578-1580.

-8 Phillips RKS, Spigelman AD: Can we safely delay or avoid prophylactic colectomy in familial adenomatous polyposis? Br J Surg 1996;83:769-770.

-9 Petersen GM, Slack J, Nakamura Y: Screening guidelines and premorbid diagnosis of familial adenomatous polyposis using linkage. Gastroenterology 1991;100:1658-1664.

10 Campbell AJ, Spence RAJ, Park TG: Familial adenomatous polyposis. Br J Surg 1994;81:1722-1733.

11 Parc YR, Olschwang S, Desaint B, Schmitt G, Parc RG, Tiret E: Familial adenomatous polyposis: prevalence of adenomas in the ileal pouch after restorative proctocolectomy. Ann Surg 2001;233:360-364.

12 Hurlstone DP, Saunders BP, Church JM: Endoscopic surveillance of the ileoanal pouch following restorative proctocolectomy for familial adenomatous polyposis. Endoscopy 2008;40:437-442.

13 Ooi BS, Remzi FH, Gramlich T, Church JM, Preen M, Fazio VW: Anal transitional zone cancer after restorative proctocolectomy and ileoanal anastomosis in familial adenomatous polyposis: report of two cases. Dis Colon Rectum 2003;46:1418-1423.

-14 Winawer S, Fletcher R, Rex D, Bond J, Burt R, Ferrucci J, Ganiats T, Levin T, Woolf S, Johnson D, Kirk L, Litin S, Simmang C; Gastrointestinal Consortium Panel: Colorectal cancer screening and surveillance: clinical guidelines and rationale - update based on new evidence. Gastroenterology 2003;124:544-560.

-15 Cruz-Correa M, Hylind LM, Romans KE, Booker SV, Giardiello FM: Long-term treatment with sulindac in familial adenomatous polyposis: a prospective cohort study. Gastroenterology 2002;122:641-645.

16 Giardiello FM, Hamilton SR, Krush AJ, Piantadosi S, Hylind LM, Celano P, Booker SV, Robinson CR, Offerhaus GJ: Treatment of colonic and rectal adenomas with sulindac in familial adenomatous polyposis. N Engl J Med 1993;328:1313-1316.

17 Steinbach G, Lynch PM, Phillips RK, Wallace MH, Hawk E, Gordon GB, Wakabayashi N, Saunders B, Shen Y, Fujimura T, Su LK, Levin B, Godio L, Patterson S, Rodriguez-Bigas MA, Jester SL, King KL, Schumacher M, Abbruzzese J, DuBois RN, Hittelman WN, Zimmerman S, Sherman JW, Kelloff G: The effect of celecoxib, a cyclooxygenase-2 inhibitor, in familial adenomatous polyposis. N Engl J Med 2000;342:1946-1952. 


\section{Case Reports in Oncology}

\begin{tabular}{l|l}
\hline Case Rep Oncol 2014;7:349-356 \\
\hline DOI: $10.1159 / 000363221$ & $\begin{array}{l}\text { C 2014 S. Karger AG, Basel } \\
\text { www.karger.com/cro }\end{array}$ \\
\hline
\end{tabular}

Murgic et al.: Familial Adenomatous Polyposis in Three Generations of a Single Family: A Case Study

Table 1. Timeline of surgical interventions for the affected family members

\begin{tabular}{|c|c|c|c|}
\hline & Case 2 (grandmother) & Case 1 (son) & Case 3 (granddaughter) \\
\hline $\begin{array}{l}\text { Age at diagnosis } \\
\text { (years) }\end{array}$ & 24 & 11 & 13 \\
\hline First procedure & $\begin{array}{l}\text { At } 24 \text { years abdominoperineal } \\
\text { resection; histology: rectal } \\
\text { adenocarcinoma with few polyps }\end{array}$ & $\begin{array}{l}\text { At } 11 \text { years subtotal colectomy with } \\
\text { ileorectal anastomosis; histology: } \\
\text { multiple polyps }\end{array}$ & $\begin{array}{l}\text { At } 14 \text { years total proctocolectomy } \\
\text { with ileoanal anastomosis; histology: } \\
\text { FAP, countless polyps with } \\
\text { high-grade dysplasia and one } \\
\text { carcinoma in situ }\end{array}$ \\
\hline Second procedure & $\begin{array}{l}\text { At } 33 \text { years correction of } \\
\text { sigmoidostomy for prolapse; } \\
\text { histology: few polyps }\end{array}$ & $\begin{array}{l}\text { At } 39 \text { years restorative proctectomy } \\
\text { with ileal pouch-anal anastomosis; } \\
\text { histology: multiple polyps with } \\
\text { high-grade dysplasia; two } \\
\text { adenocarcinomas (T2N0Mx G2, } \\
\text { T1N0Mx G2) }\end{array}$ & - \\
\hline Third procedure & $\begin{array}{l}\text { At } 42 \text { years total colectomy with } \\
\text { Kock's reservoir; histology: colon } \\
\text { polyposis with numerous } \\
\text { tubulovilluos adenomas with } \\
\text { high-grade dysplasia }\end{array}$ & $\begin{array}{l}\text { At } 41 \text { years abdominoperineal } \\
\text { resection; histology: recurrent rectal } \\
\text { adenocarcinoma (LNR 3/4) followed } \\
\text { by RT/5FU/L }\end{array}$ & - \\
\hline Extra-colonic disease & $\begin{array}{l}\text { At } 45 \text { years adenoma of parathyroid } \\
\text { was removed; histology: parathyroid } \\
\text { adenoma } \\
\text { At } 55 \text { years duodenal polypectomy; } \\
\text { histology: adenovillous polyp } \\
\text { At } 57 \text { years duodenal polypectomy; } \\
\text { histology: villous adenoma with } \\
\text { adenocarcinoma } \\
\text { At } 63 \text { years gastric polyp; histology: } \\
\text { adenomatous polyp with high-grade } \\
\text { dysplasia } \\
\text { At } 65 \text { years duodenal polyp; } \\
\text { histology: adenomatous polyp }\end{array}$ & $\begin{array}{l}\text { At } 43 \text { years progression with } \\
\text { multiple liver and lung metastases } \\
\text { followed by XELIRI-bevacizumab } \\
\text { chemotherapy }\end{array}$ & $\begin{array}{l}\text { At } 15 \text { years total thyroidectomy; } \\
\text { histology: papillary thyroid cancer } \\
\text { At } 15 \text { years polypectomy of } \\
\text { duodenal polyp; histology: tubular } \\
\text { adenoma }\end{array}$ \\
\hline
\end{tabular}

Genetic testing in all three patients revealed a $2805 \mathrm{C}>\mathrm{G}$ substitution. $\mathrm{LNR}=\mathrm{Lymph}$ node ratio; RT $/ 5 \mathrm{FU} / \mathrm{L}=$ radiotherapy concomitantly with 5-FU and leucovorin chemotherapy; XELIRI = capecitabine plus irinotecan. 
Murgic et al.: Familial Adenomatous Polyposis in Three Generations of a Single Family: A Case Study

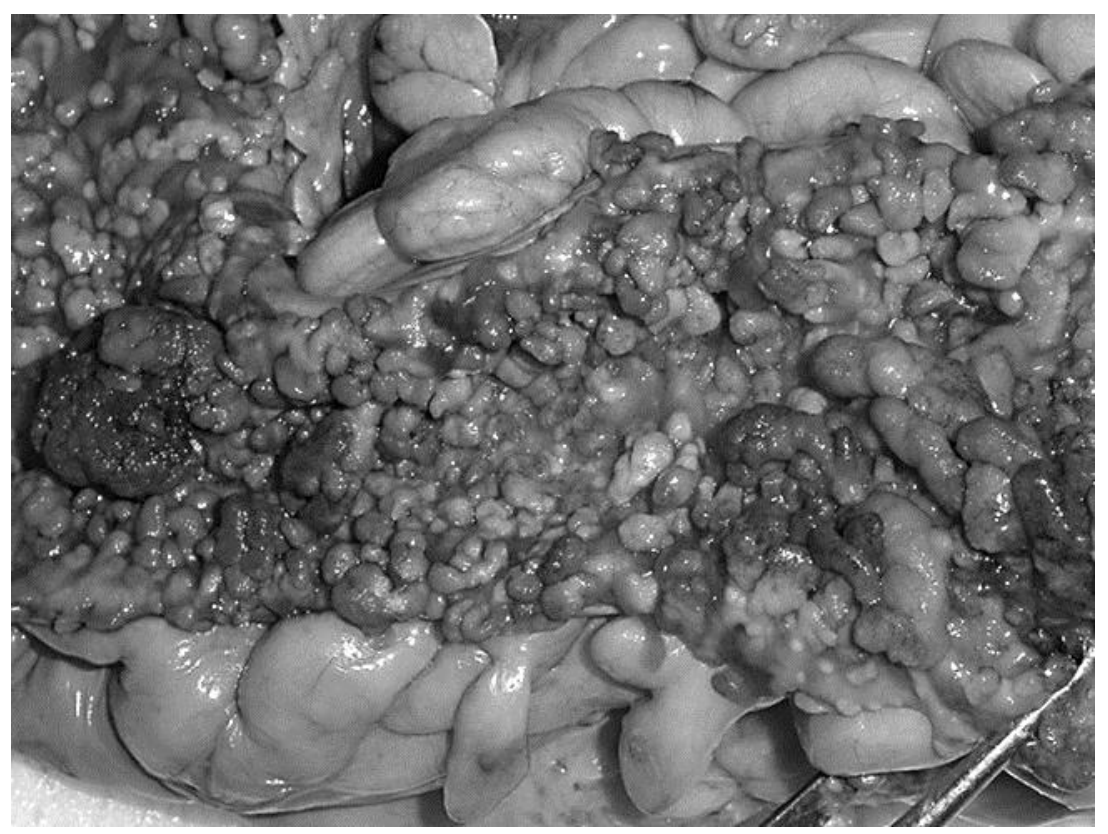

Fig. 1. Countless polyps carpeting the mucosal surface of the resected rectum.

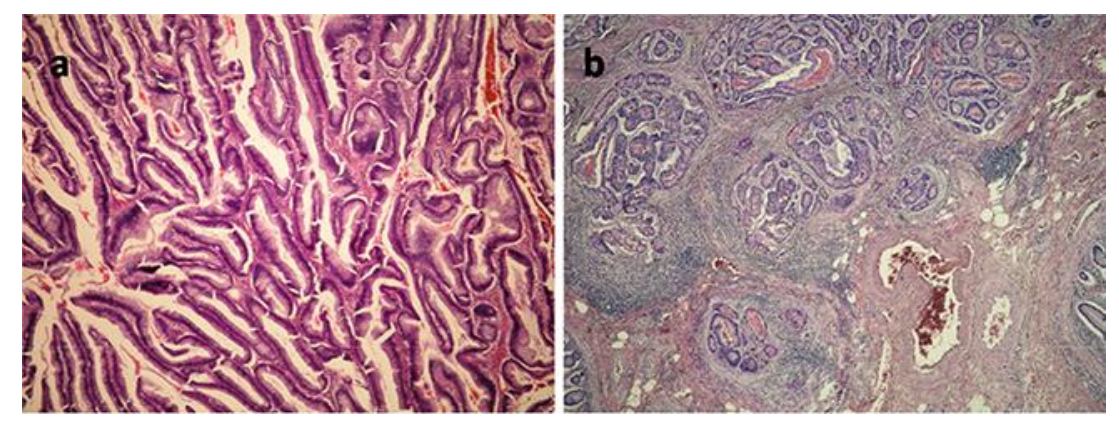

Fig. 2. a Villous adenoma with high-grade epithelial dysplasia (HE. ×40). b Adenocarcinoma infiltrating the submucosa $($ HE. $\times 40)$. 
Murgic et al.: Familial Adenomatous Polyposis in Three Generations of a Single Family: A Case Study

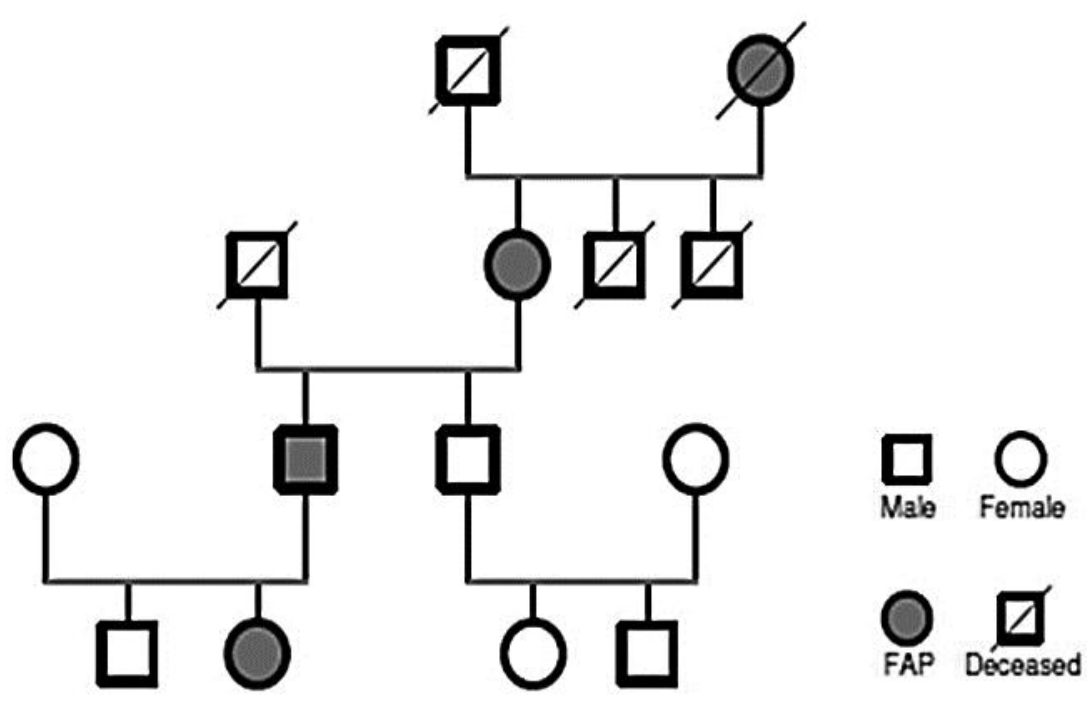

Fig. 3. Family pedigree chart. 